\title{
Studies on Pitch Problems Caused by Pulping and Bleaching of Tropical Woods. XIV.* Chemistry of the Aurone Derivatives at the Conventional Bleaching Stages
}

\author{
YOSHITO OHTANI and MASASHI SUMIMOTO
}

Faculty of Agriculture, Kyushu University, Higashi-ku Hakozaki, Fukuoka 812, Japan

Rengasin (1), which is responsible for the colored specks on a sheet of bleached sulfate pulp from the woods of rengas (Anacardiaceae), was converted into $R_{1} 7$ having a novel carbon skeleton. A closely related analogue, $S_{1} 8$, prepared from sulfuretin (2) was used as a model to investigate further conversions under bleaching conditions. Chlorination of $\mathrm{S}_{1} 8$ produced an equilibrium mixture involving compound 9 as a dominant compound. The latter was transformed by the treatment with chlorine dioxide into an orthoquinone (16) via two pathways containing 10 in one and 15 in another. The monomeric quinone (16) immediately dimerized in acidic media to give 20 under the same conditions as above, and the further oligomerization by the process similar to that in dimerization of 16 finally afforded a mixture of colored oligomers 26 .

Some characteristic phenomena as regards the formation of brown pitch specks on sheets of bleached sulfate pulps (BKP) from rengas wood (Gluta or Melanorrhoea sp., Anacardiaceae) grown in Sarawak and their exclusion from the pulps were mentioned in our previous papers. ${ }^{1,2}$ Rengasin (1) responsible for the brown specks was chemically converted during the alkaline cooking and subsequent bleaching stages into the final colored specks, while the latter were effectively removed by application of a phase transfer catalyst to the alkaline extraction stage in the conventional multistage bleaching. This proves that all the conversion reactions of rengasin (1) proceeded in

* Part XIII. Mokuzai Gakkaishi. 28 (1982) 452. the interior of the neutral hydrophobic membrane formed with the components of wood extractives. As for the chemical conversion of rengasin (1) during the cooking stage, 4-methoxy-6-hydroxycoumaranone (3), protocatechualdehyde (5), and an intermediate $R_{1}(7)$ were isolated from the pulp extractives but not from the wood extractives. This seems to indicate the presence of a thermal equilibrium ${ }^{3}$ among these compounds which is slightly different from the scheme shown in Fig. 1. Sulfuretin (2) is not only a closely related derivative of rengasin (1) but also responsible for colored pitch specks on sheets of BKP from the wood of sepetir paya (Pseudosindora palustris). ${ }^{4}$ Sulfuretin also affords intermediate $\mathrm{S}_{1} 8^{5}$ as a component of an equilibrium system similar to that involving $R_{1} 7$ formed from rengasin (1). In the present paper, therefore, intermediate $S_{1} 8$ was adopted as one of the aurones to elucidate the mechanism for the formation of colored specks during the bleaching stages, since $S_{1}$ can be synthesized more readily than $\mathrm{R}_{1}$. Although the colored specks can be produced by treatment with chlorine dioxide $\left(\mathrm{ClO}_{2}\right)$ alone, it has been suggested ${ }^{1}$ that chlorination prior to the $\mathrm{ClO}_{2}$ treatment plays an important role in making stable colored specks. The chlorination of $\mathrm{S}_{1}$ will be discussed first under these considerations.

\section{RESULTS AND DISCUSSION}

Treatment of $S_{1} 8$ with chlorine. Although chlorination of 8 at $25^{\circ} \mathrm{C}$ was found to be nearly completed within twenty minutes as confirmed by thin layer chromatography (TLC), the reaction was 


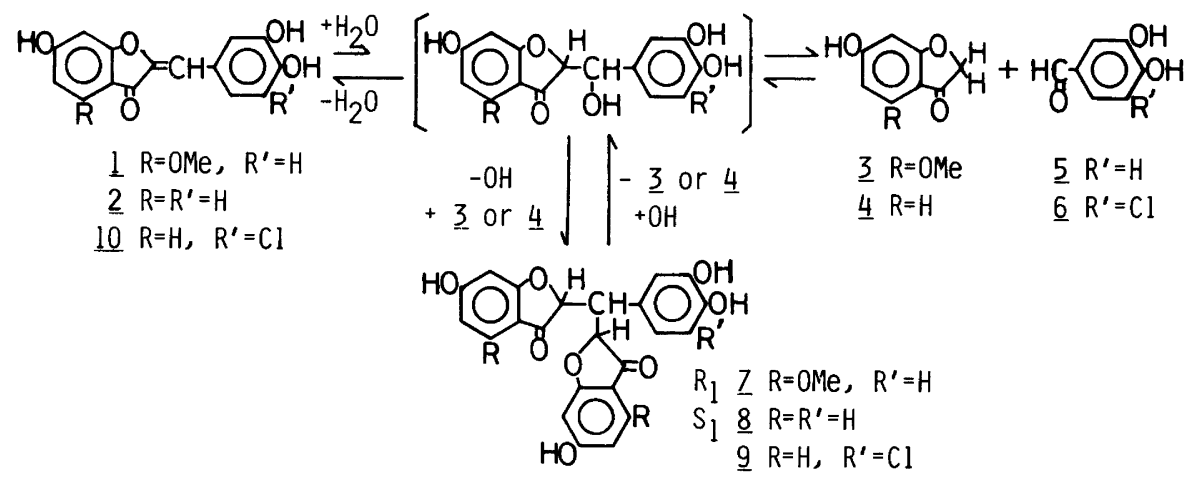

Fig. 1. Acid-catalyzed equilibria between aurones (1,2 and 10) and coumaranone adducts (7, 8 and 9$)$.

continued for a further twenty minutes. The resulting products were chromatographed on a silica-gel column to separate into seven fractions. The contributing yields and $\operatorname{ratios}^{1}$ of the individual fractions to the total speck area are shown in Table 1. Fractions 2 and 3 were crystallized and identified as 6-hydroxy-coumaranone (4) and 5-chloroprotocatechualdehyde (6), respectively. In another experiment, the authentic sample of 6 for identification was synthesized by chlorination of protocatechualdehyde (5). Fraction 4, showing the highest yield as well as the highest contributing ratio, also gave crystalline compound 9 whose mass spedctrum and elemental analysis are consistent with molecular formula $\mathrm{C}_{23} \mathrm{H}_{15} \mathrm{O}_{8} \mathrm{Cl}$. Its mass fragmentation pattern was quite similar to that of $\mathrm{S}_{1}$ 8 and $R_{1} 7^{3}$ and, therefore, suggested the presence of a chlorine atom in the B-ring of the same carbon

Table 1. Yields and contribution ratios of each fraction separated from the chlorinated mixture of 8 to the total speck areas.

\begin{tabular}{llrr}
\hline $\begin{array}{l}\text { Fraction } \\
\text { number }\end{array}$ & Compound & $\mathrm{A}^{a}$ & \multicolumn{1}{c}{$\mathrm{B}$} \\
\hline 1 & & 8.6 & 5.8 \\
2 & 4 & 19.7 & 17.1 \\
3 & 6 & 13.7 & 15.3 \\
4 & 9 & 29.2 & 35.8 \\
5 & & 3.3 & 3.5 \\
6 & & 8.7 & 10.1 \\
7 & & 11.6 & 12.4 \\
\hline
\end{tabular}

${ }^{a} \mathrm{~A}$, Yield (weight percent to the total chlorinated mixture). B, Contribution ratio to the total speck areas (percent). skeleton as that of $S_{1} 8$. Spectral data obtained by ${ }^{13} \mathrm{C}$ nuclear magnetic resonance (CMR) of acetates $11,13,12$ and 14, all of which have been prepared by acetylation of 2,8,5'-chloro-sulfuretin (10), and 9, respectively, are summarized in Table 2 and their numbering system is given in Fig. 2. Assignments of

Table 2. Comparison of ${ }^{13} \mathrm{C}$ NMR spectral data (ppm from TMS) of the acetates 11,12,13, and 14 in DMSO- $d_{6}$.

\begin{tabular}{lllll}
\hline Carbon & 11 & 12 & 13 & 14 \\
\hline 2 & 146.80 & 147.77 & 151.67 & 151.71 \\
3 & 182.18 & 182.18 & 143.20 & 143.19 \\
$3 \mathrm{a}$ & 124.20 & 127.71 & 120.42 & 120.41 \\
4 & 125.24 & 125.66 & 130.96 & 131.22 \\
5 & 110.50 & 107.47 & 119.27 & 119.47 \\
6 & 166.00 & 166.26 & 148.38 & 148.53 \\
7 & 107.21 & 104.66 & 117.93 & 118.06 \\
$7 \mathrm{a}$ & 167.88 & 166.96 & 148.40 & 148.54 \\
$\alpha$ & 118.35 & 118.00 & 106.05 & 106.09 \\
& & & & \\
$1^{\prime}$ & 142.17 & 142.17 & 134.62 & 135.62 \\
$2^{\prime}$ & 125.85 & 124.38 & 123.90 & 122.05 \\
$3^{\prime}$ & 143.08 & 143.08 & 141.50 & 143.72 \\
$4^{\prime}$ & 157.40 & 157.78 & 141.99 & 139.61 \\
$5^{\prime}$ & 129.75 & 148.30 & 123.90 & 142.61 \\
$6^{\prime}$ & 130.41 & 130.46 & 112.76 & 127.34 \\
& & & & \\
$2^{\prime \prime}$ & - & - & 151.67 & 151.71 \\
$3^{\prime \prime}$ & - & - & 143.20 & 143.19 \\
$3 \mathrm{a}^{\prime \prime}$ & - & - & 120.42 & 120.41 \\
$4^{\prime \prime}$ & - & - & 130.96 & 131.22 \\
$5^{\prime \prime}$ & - & - & 119.27 & 119.47 \\
$6^{\prime \prime}$ & - & - & 148.38 & 148.53 \\
$7^{\prime \prime}$ & - & - & 117.93 & 118.06 \\
$7 \mathrm{a}^{\prime \prime}$ & - & - & 148.40 & 148.54 \\
\hline
\end{tabular}

Acta Chem. Scand. B 36 (1982) No. 9 


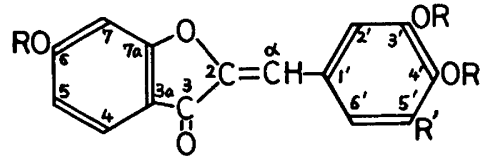

$11 \mathrm{R}=\mathrm{COCH}_{3}, \mathrm{R}^{\prime}=\mathrm{H}$

$12 \mathrm{R}=\mathrm{COCH}_{3}, \mathrm{R}^{\prime}=\mathrm{Cl}$

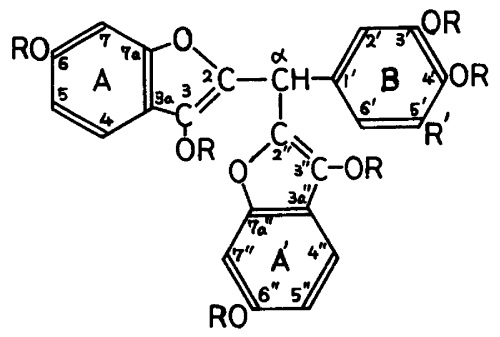

$13 \mathrm{R}=\mathrm{COCH}_{3}, \mathrm{R}^{\prime}=\mathrm{H}$

$14 \mathrm{R}=\mathrm{COCH}_{3}, \mathrm{R}^{\prime}=\mathrm{Cl}$

Fig. 2. The acetates of the compounds 2,10,8 and 9.

the signals were carefully made in reference to the CMR spectral data with those of aurone derivatives ${ }^{6}$ and flavone derivatives. ${ }^{7}$ All of the signals due to 23 carbons of 14 show $\delta$-values almost identical with those of 13 but one due to $5^{\prime}$-carbon. The latter signal demonstrates a remarkable downfield shift compared to the corresponding signal for 13 , which is nearly in accordance with a difference in resonance field between the $5^{\prime}$-carbon signals of 11 and 12 . However, the unusually high down-field shift caused by the substituted chlorine atom is known as a characteristic feature of a tri-substituted B-ring. ${ }^{8}$ The above results are, therefore, consistent with structure 14. A further evidence for structure 9 was provided by the alkaline fission of the compound to afford 6-hydroxy-coumaranone (4) and 5'-chlorosulfuretin (10). The fission mode is in good agreement with those of $R_{1} 7^{3}$ and $S_{1} 8 .^{5}$ The authentic sample of $5^{\prime}$-chloro-sulfuretin (10) for identification was synthesized independently by condensation of 6-hydroxy-coumaranone (4) with 5chloro-protocatechualdehyde (6) in the usual manner. In the light of the accumulated spectral and chemical evidence, structure 9 was assigned to the major chlorination product from $S_{1} 7$.

Since the chlorination mixture at $25^{\circ} \mathrm{C}$ was confirmed to contain 4 and 6 together with 9, an equilibrium shown in Fig. 1 must be established. In this case, however, $5^{\prime}$-chloro-sulfuretin (10) was not detected in spite of our expectation. As has been already mentioned, ${ }^{3}$ a methanolic solution of 4 and 5 , which was adjusted to $\mathrm{pH} 2.5$ by adding hydrochloric acid at room temperature, gave $\mathrm{S}_{1} 8$ in a $15 \%$ yield. When a methanolic solution of 6 hydroxy-coumaranone (4) and 5-chloroprotocatechualdehyde (6) was treated in the manner as mentioned above, it afforded 10 and 9 in 13.4 and $9.1 \%$ yields, respectively. These findings actually indicate the presence of an equilibrium during the chlorination as shown in Fig. 1, and allow one to propose that 10 produced in a low yield on chlorination of $\mathrm{S}_{1} 8$ immediately undergoes the addition of chlorine to its double bond, followed by an oxidative cleavage. As shown in Fig. 1, however, the equilibrium system in acidic media at the present low temperature must involve some other reaction pathway different from that in neutral media at $170^{\circ} \mathrm{C}$ shown in our previous paper. ${ }^{5}$ In any case, occurrence of the equilibrium may be primarily attributed to the somewhat sterically unstable nature of bonds around the tertiary carbon atoms placed at the center of the molecules, 8,7 and 9 .

Chlorine dioxide treatment of 9 . Chlorine dioxide prepared as a bleaching agent in the laboratory as well as in the bleach plant generally contains a few percent of chlorine ${ }^{9}$ which lowers the $\mathrm{pH}$ of bleaching liquor to about $4.0-4.5$, and the reaction temperature is usually maintained at $60^{\circ} \mathrm{C}$.

When a methanolic solution of $9(1.0 \mathrm{mmol})$ was adjusted by dilute hydrochloric acid to $\mathrm{pH} 4.0$ and kept at $60^{\circ} \mathrm{C}$ for ten to ninety minutes, the resulting mixture afforded $c a .0 .5 \mathrm{mmol}$ of $10,0.4 \mathrm{mmol}$ of 9 , and $0.4 \mathrm{mmol}$ of 4 regardless of duration of the reaction. The constant yields of the above compounds, therefore, prove that a certain equilibrium is achieved immediately at that temperature. However, the equilibrium thus attained is in favor of the formation of 10 relative to the case when $S_{1} 8$ is chlorinated at such a low temperature and $\mathrm{pH}$. As mentioned in the previous section, 5 '-chloro-sulfuretin (10) cannot be obtained by direct chlorination of sulfuretin (2) but only by a splitting reaction from 9 at the stage of $\mathrm{ClO}_{2}$ treatment.

When 9 was treated with $\mathrm{ClO}_{2}$ in $t$-butanol - water for ten minutes at $60^{\circ} \mathrm{C}$, the reddish quinoid compound (15) was furnished in a yield of $18.2 \%$. Its IR ${ }^{10}$ and UV spectra ${ }^{11}$ indicate an ortho-quinone structure. Reduction of 15 with sodium borohydride $\left(\mathrm{NaBH}_{4}\right)$ afforded 9 as a sole product. The quinoid compound is, therefore, formulated as 15 . When 15 was further treated at 


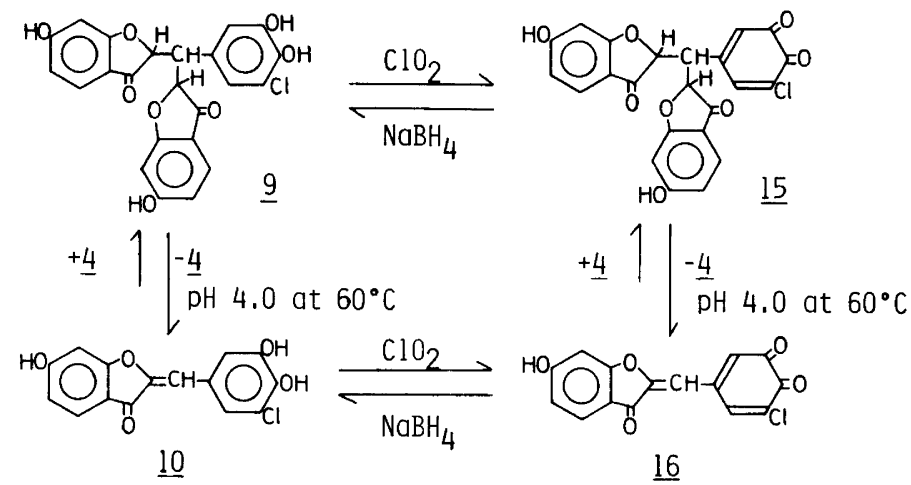

Fig. 3. Transformation of 9 to 16 in the reaction media with $\mathrm{ClO}_{2}$.

$60{ }^{\circ} \mathrm{C}$ in weakly-acidic media, it underwent a fission to give 6-hydroxy-coumaranone (4) along with the formation of another reddish product. The latter was also confirmed to be an ortho-quinone by spectral data and reduced with $\mathrm{NaBH}_{4}$ to afford 10 . Accordingly, the second quinone must have structure 16 .

On the other hand, compound 16 was also obtained in a relatively high yield by oxidation of 10 with $\mathrm{ClO}_{2}$. After all, a major fraction of 9 , the dominant product on chlorination of $\mathrm{S}_{1}$, can be transformed into 16 by the treatment with $\mathrm{ClO}_{2}$ via the two different pathways as shown in Fig. 3. In other words, as a result of the complete chemical conversion of 2 caused by cooking during the bleaching process, an important intermediate (16) was produced in a comparatively high yield. While 16 is stabilized by the chlorine substituent ${ }^{12}$ at $5^{\prime}$ position, it can be subjected further to an acidcatalyzed oligomerization by treatment with $\mathrm{ClO}_{2}$. However, the intermediate (16) used for the experiments in later sections was prepared by oxidation of 10 with sodium metaperiodate $\left(\mathrm{NaIO}_{4}\right){ }^{13}$ because $\mathrm{ClO}_{2}$ oxidation of 10 was accompanied by some undesirable reactions.

Reaction of 16 in weakly-acidic media. A further reaction of 16 in weakly-acidic media at $60^{\circ} \mathrm{C}$ afforded four products as confirmed by TLC of the reaction mixture. Quantitative analysis of these products at various lengths of reaction time was performed by using a chromato-scanner. The products were designated as I-IV on the basis of the magnitude of $R_{\mathrm{F}}$ values on TLC in a decreasing order, IV being zero. The changes in yields of these components are shown in Fig. 4. While the starting material (16) rapidly decreases within five minutes,
III appeared instantaneously and increased until the elapse of thirty minutes, and decreased gradually thereafter. In contrast, the reddish product (IV) increased slowly. In fact, the direct conversion of III to the final product (IV) was achieved under the same conditions as above and this proves that the former is one of the major precursors for the latter. The chemical structure for III is to be discussed in the next section. Component II, which appeared fifteen minutes after the initiation of reaction, was obtained but in a low yield and identified as 10 . This suggests the occurrence of some intermolecular oxidation-reduction, though the detail is still unknown.

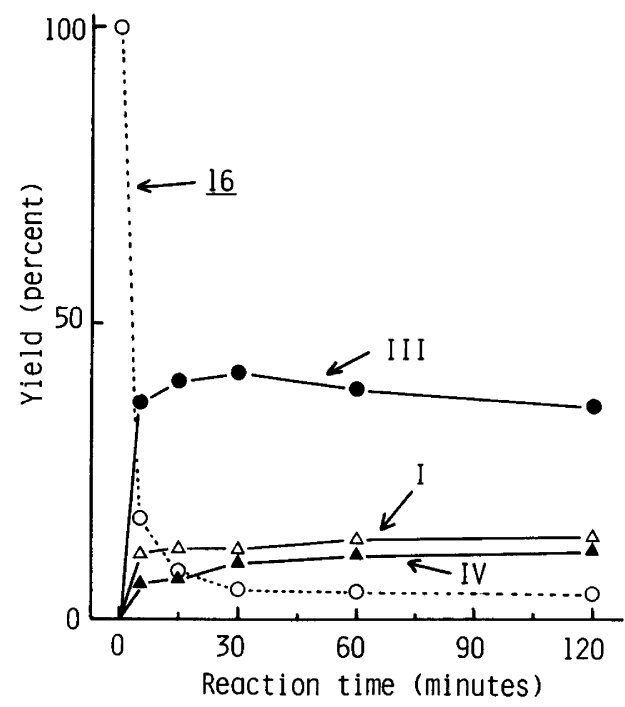

Fig. 4. Change in the yields of I, III and IV obtained from the reaction mixture of 16 . 


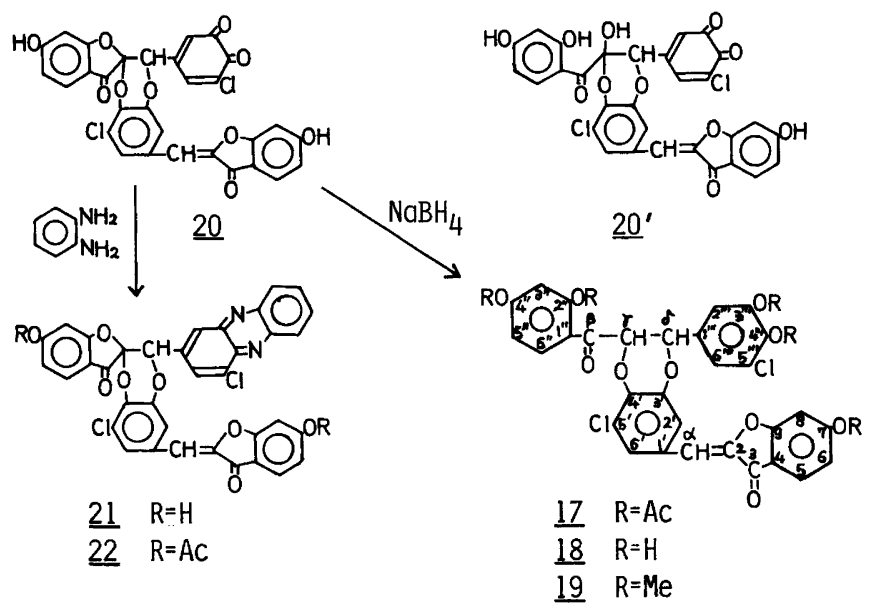

Fig. 5. The dimer III 20 and the derivatives.

The chemical structure for III. The reddish crystalline compound (III) obtained by reaction of 16 in weakly-acidic media, is taken as the direct precursor for the final product (IV). However, III is unfortunately too labile in the free form to be purified. The compound (III) was, therefore, reduced with $\mathrm{NaBH}_{4}$, and then acetylated with acetic anhydride and pyridine to afford 17 . Its FD and CMR spectra indicated that the product has a carbon skeleton of $5^{\prime}$-chloro-sulfuretin (10). On the basis of its ${ }^{1} \mathrm{H}$ NMR spectrum (PMR), which revealed signals due to two vicinal methine protons, chemical structure 17 was assigned to the acetate. To confirm this, reduction product 18 from III was methylated with dimethyl sulfate and potassium carbonate in acetone, and the resulting methyl ether $19(420 \mathrm{mg})$ was ozonized. This was followed by decomposition of the ozonide with hydrogen peroxide and acetic acid to afford $38 \mathrm{mg}$ of 4- methoxy-salicylic acid (23), $23 \mathrm{mg}$ of 2,4-dimethoxybenzoic acid (24), and $135 \mathrm{mg}$ of an unknown mixture. The latter mixture was, therefore, oxidized further with alkaline permanganate and yielded solely $10 \mathrm{mg}$ of 5-chloro-veratric acid (25). As shown in Fig. 5, 23, 24 and 25 must originate from rings $A$, $\mathbf{A}^{\prime}$ and $\mathbf{B}^{\prime}$ of 19 , respectively. The extent of yields and that of procurement of the acids under the experimental conditions may allow structure 19 to be satisfactorily assigned to the methyl ether, and hence, structure 18 to the reduction product from III. This leads to confine possible chemical structures for III, an ortho-quinonoid compound, to 20 and $20^{\prime}$. It is conceivable that structure $20^{\prime}$ accounts better than 20 for the ready reduction to 17 , but it may not for the stable feature toward an oxidant, $\mathrm{ClO}_{2}$. However, III afforded a phenylenediamine adduct 21 under mild conditions and the latter produced a stable crystalline acetate

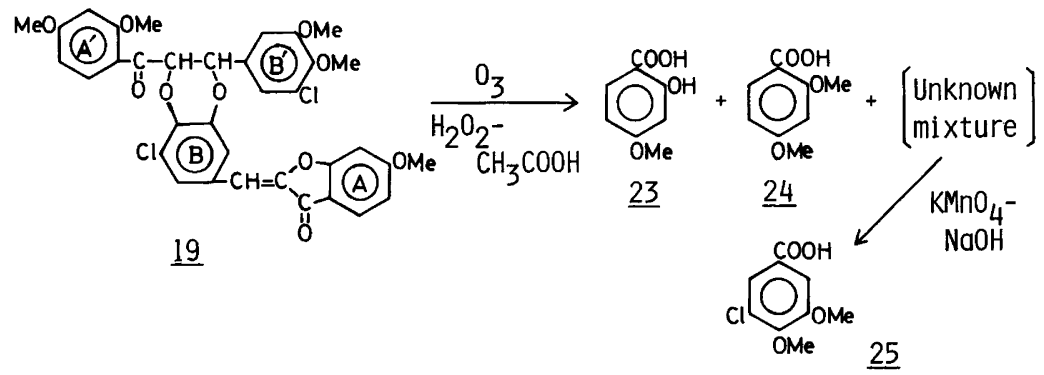

Fig. 6. Degradation of the methyl ether 19.

Acta Chem. Scand. B 36 (1982) No. 9 


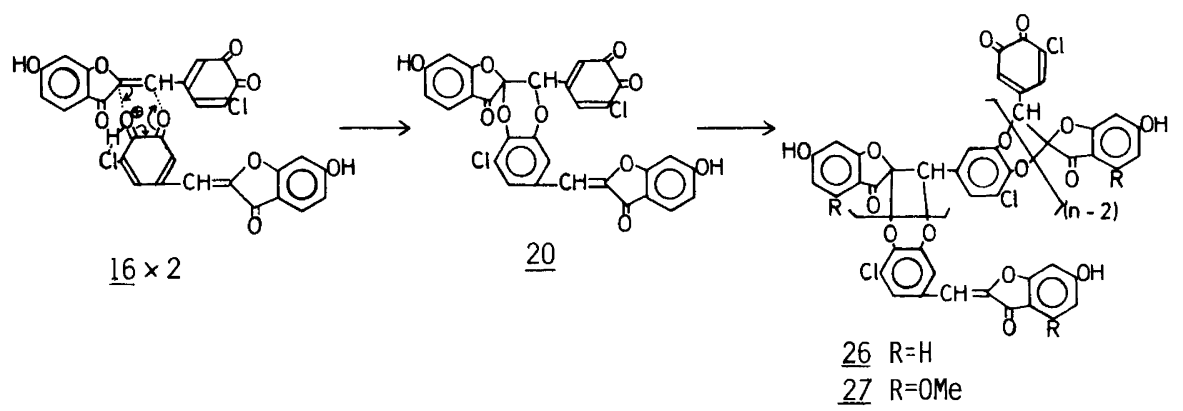

Fig. 7. Condensation of 16 via the dimer 20 to the final oligomers 26.

(22). The PMR spectrum of the crystalline acetate revealed proton signals due to two acetoxyl groups and one methine proton, as a singlet, fully corresponding to structure 22. The elemental analysis was also consistent with 22 . Based on the findings mentioned above, structure 20 for III is preferred to $20^{\prime}$.

It has been generally realized that the orthoquinone undergoes two types of condensation reactions, one is the diene addition ${ }^{13,14}$ between two quinone rings through the Diels-Alder process, and another is the formation of benzodioxene derivatives. ${ }^{15-17}$ However, the third type of intermolecular condensation through acidcatalyzed oxidation-reduction between a quinone and a phenolic moiety has been reported very recently from our laboratory. ${ }^{18}$ Therefore, the formation of the dimer (20) apparently belongs to the second type which is also an acid-catalyzed condensation as shown in Fig. 7. Nevertheless, the PMR spectrum of impure dimer III disclosed signals corresponding to those of methine protons, ${ }^{14}$ which may be derived from the products furnished by the first type of reaction. Therefore, dimer III, having difficulty in purification, may be contaminated by a small amount of dimers produced by the DielsAlder process.

The colored oligomers, IV. The elemental and chlorine analyses of the final product (IV) separated by column chromatography proved that the elemental composition was in good agreement with that of 16. The UV and IR spectra of IV are quite similar to those of 20 . Reduction of IV with $\mathrm{NaBH}_{4}$ followed by acetylation gave the product, whose CMR spectrum is almost identical with that of 17 and particularly indicates signals referred to $\beta, \gamma$, and $\delta$ carbons. The numbering system for the skeletal carbon atoms of 17 is shown in Fig. 5. The colored substance (IV) apparently consists of a mixture of oligomers of 16 . The oligomerization seems to proceed by the same process as dimerization of 16 to give 20. This leads us to postulate structure 26 for IV as shown in Fig. 7. However, the gel-permeation chromatogram of 26 indicated the molecular weights of the predominant fractions to be about $1500-2000$, corresponding to the pentamer or hexamer of 16 . Accordingly, the color of IV is developed only from the terminal ortho-quinone in 26.

It must be emphasized again that the complete chemical conversions mentioned above proceed in the interior of the neutral hydrophobic membrane, through which chlorine and $\mathrm{ClO}_{2}$ penetrate. ${ }^{19}$ The final oligomers (26) are almost insoluble in many organic solvents, in a manner similar to that observed for the colored specks which appeared on sheets of BKP from the wood of rengas as well as sepetir paya. ${ }^{4}$ The oligomers (26) and conceivable analogues 27 originated from rengasin 1 are, therefore, suggested to constitute one of the major parts of the colored speks in the pulps from sepetir paya and rengas, respectively.

\section{CONCLUSION}

The chemical conversions of $S_{1} 8$ to the final colored oligomers (26) occurred through bleaching reactions were discussed. The dominant product (9) at the chlorination stage is transformed via two pathways into 5 '-chloro-sulfuretin quinone (16) as the major product at the early stage of $\mathrm{ClO}_{2}$ treatment. However, the monomeric quinone (16) readily undergoes condensation in acidic media to the dimer (20) and then gradually to the final colored oligomers (26) at the later stage of $\mathrm{ClO}_{2}$ treatment. 
The latter (26) and its plausible analogues 27 are suggested to be one of the major constituents of the colored specks in BKP's from the woods of sepetir paya and rengas, respectively.

\section{EXPERIMENTAL}

Synthesis of $S_{1} 8$. This was prepared by the method used for the synthesis of $R_{1} 7 .^{3}$ The product obtained by the treatment of the compounds (4) and (5) with $0.5 \mathrm{~N}$ HCl-methanol $(\mathrm{MeOH})$ was chromatographed on silica-gel column (benzene - ethyl acetate - formic acid = 10:4:1, designated as solvent A to afford the fraction, recrystallization of which from $\mathrm{MeOH}$ furnished $\mathrm{S}_{1} 8$. (Yield $11.0 \%$, m.p. (d.p.) $275^{\circ} \mathrm{C}$.

Chlorination of $S_{1} 8 . \mathrm{S}_{1} 8(2.0 \mathrm{~g})$ was dissolved in $200 \mathrm{ml}$ of $t$-butanol (t-BuOH), to which $200 \mathrm{ml}$ of aqueous chlorine solution $(24 \mathrm{mmol})$ was added under stirring. After $40 \mathrm{~min}$ the solution was neutralized and evaporated to small volume under reduced pressure and the residual solution was extracted with ethyl acetate (EtOAc). The EtOAc solution was washed sufficiently with water and then evaporated to dryness. The residue $(2.4 \mathrm{~g})$ was separated on a silica-gel column (solvent A) into seven fractions. Each fraction was subjected to determination of the contributing ratio to the total speck area according to the previous method. ${ }^{1}$ Among them Fraction 2 was recrystallized from $\mathrm{MeOH}$ to afford orange plates $(260 \mathrm{mg}$ ), having m.p. $245-247^{\circ} \mathrm{C}$. This was identified as 6-hydroxycoumaranone (4) by comparing the m.p. mixed m.p., and IR spectra with those of the authentic sample. Fraction 3 was recrystallized from $\mathrm{MeOH}-\mathrm{H}_{2} \mathrm{O}$ to afford white powder $(150 \mathrm{mg})$, m.p. $228-230^{\circ} \mathrm{C}$. MS: $172(\mathrm{M})$. Found: C 48.46; H 3.12. Calc. for $\mathrm{C}_{7} \mathrm{H}_{5} \mathrm{O}_{3} \mathrm{Cl}$ : C 48.52; $\mathrm{H}$ 2.91. UV [abs. $\mathrm{MeOH}(\log$ $\varepsilon)]: 240$ (3.18), 291 (3.12), 328 (2.88) nm. IR (KBr): $1640,1590,770 \mathrm{~cm}^{-1} \cdot{ }^{1} \mathrm{H}$ NMR $\left(\mathrm{CDCl}_{3}\right): \delta 9.73(1 \mathrm{H}$, $\mathrm{s}, \mathrm{CHO}), 7.37(1 \mathrm{H}, \mathrm{d}, J 2.0 \mathrm{~Hz}), 7.28(1 \mathrm{H}, \mathrm{d}, J 2.0 \mathrm{~Hz})$. The results and direct comparison to the authentic sample confirmed the identity with 5-chloroprotocatechualdehyde (6). ${ }^{20}$ The authentic sample (6) was prepared by direct chlorination of the compound (5) in $t$ - $\mathrm{BuOH}-\mathrm{H}_{2} \mathrm{O}$ followed by chromatography on silica-gel column (solvent $\mathrm{A}$ ) (yield $12 \%$ ). Fraction 4 was recrystallized from $\mathrm{MeOH}$ to afford white powder $9(550 \mathrm{mg})$, m.p. over $270^{\circ} \mathrm{C}$. MS: $454(\mathrm{M}), 304,269,168,150,121$. Found: C 59.12; $\mathrm{H}$ 3.21. Calc. for $\mathrm{C}_{23} \mathrm{H}_{15} \mathrm{O}_{8} \mathrm{Cl} .1 / 2 \mathrm{H}_{2} \mathrm{O}: \mathrm{C}$ 59.55; H 3.48. UV [abs. $\mathrm{MeOH}(\log \varepsilon)]: 230$ (4.27), 276 (4.15), $317(3.95) \mathrm{nm}$. IR (KBr): 1680, 1590, 1420, $800 \mathrm{~cm}^{-1} .{ }^{1} \mathrm{H}$ NMR (DMSO-d $\left.d_{6}\right): \delta 3.42(1 \mathrm{H}, \mathrm{q}, J 8$

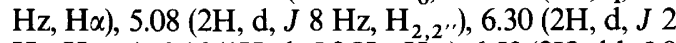
$\left.\mathrm{Hz}, \mathrm{H}_{7,7^{\prime \prime}}\right), 6.46\left(1 \mathrm{H}, \mathrm{d}, J 2 \mathrm{~Hz}, \mathrm{H}_{2}\right), 6.52(2 \mathrm{H}, \mathrm{dd}, J 8$
$\left.\mathrm{Hz}, \mathrm{H}_{5,5^{\prime \prime}}\right), 7.06\left(1 \mathrm{H}, \mathrm{d}, J 2 \mathrm{~Hz}, \mathrm{H}_{6}{ }^{\prime}\right), 7.40$ (2H, s, $J 8$

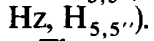

The compound (9) was acetylated with acetic anhydride and pyridine to produce the acetate, which was recrystallized from isopropyl ether to afford white crystalline powder 14, m.p. 168 $-170^{\circ} \mathrm{C}$. MS: $706(\mathrm{M})$. Found: C 54.23; H 3.98 . Calc. for $\mathrm{C}_{23} \mathrm{H}_{9} \mathrm{O}_{2} \mathrm{Cl}\left(\mathrm{OCOCH}_{3}\right)_{6}: \mathrm{C} 54.54 ; \mathrm{H} 3.85$. UV [abs. MeOH (log $\varepsilon)]: 254$ (4.15), 311 (4.12), 371 (3.94) nm. IR (KBr): $1760,1610,1480,890,810 \mathrm{~cm}^{-1}$. ${ }^{1} \mathrm{H} \mathrm{NMR}\left(\mathrm{CDCl}_{3}\right): \delta 2.06(6 \mathrm{H}, \mathrm{s}, \mathrm{OAc} \times 2), 2.31(12 \mathrm{H}$, $\mathrm{s}, \mathrm{OAc} \times 4), 6.34(1 \mathrm{H}, \mathrm{s}, \mathrm{H} \alpha), 6.96(2 \mathrm{H}, \mathrm{dd}, J 8 \mathrm{~Hz}$, $\left.\mathrm{H}_{5,5^{\prime \prime}}\right), 7.18\left(2 \mathrm{H}, \mathrm{d}, J 2 \mathrm{~Hz}, \mathrm{H}_{7,7^{\prime \prime}}\right), 7.24(1 \mathrm{H}, \mathrm{d}, J 2 \mathrm{~Hz}$, $\left.\mathrm{H}_{6}\right), 7.30\left(2 \mathrm{H}, \mathrm{d}, J 8 \mathrm{~Hz}, \mathrm{H}_{4,4^{\prime \prime}}\right), 7.35(1 \mathrm{H}, \mathrm{d}, J 2 \mathrm{~Hz}$, $\mathrm{H}_{2}$,). The chemical shifts of its ${ }^{13} \mathrm{C}$ NMR spectrum were shown in Table 2 , and all ${ }^{13} \mathrm{C}$ NMR spectra were measured in DMSO- $d_{6}$ with tetramethylsilane as an internal standard.

The compound (9) $(230 \mathrm{mg}$ ) was dissolved in $15 \%$ $\mathrm{KOH}-\mathrm{MeOH}$ and refluxed for an hour. The solution was acidified and extracted with EtOAc. The extracts evaporated were chromatographed on silica-gel column (solvent A) to afford two compounds. The one $(45 \mathrm{mg})$ was identified as 6hydroxy-coumaranone (4) and the other was recrystallized from $\mathrm{MeOH}-\mathrm{H}_{2} \mathrm{O}$ to afford yellow powder (58 mg), m.p. over $270^{\circ} \mathrm{C}$. MS $305(\mathrm{M}), 270$ $(\mathrm{M}-35), 150$. Found: C 54.36; H 3.59. Calc. for $\mathrm{C}_{15} \mathrm{H}_{9} \mathrm{O}_{5} \mathrm{Cl} \cdot 3 / 2 \mathrm{H}_{2} \mathrm{O}: \mathrm{C} 54.31 ; \mathrm{H}$ 3.64. UV [abs. MeOH (log $\varepsilon)]: 259$ (3.82), 390 (4.01) nm. IR (KBr): $1680,1580,810 \mathrm{~cm}^{-1} .{ }^{1} \mathrm{H}$ NMR (DMSO- $d_{6}$ ): $\delta 6.72$ $\left(1 \mathrm{H}, \mathrm{dd}, J 8 \mathrm{~Hz}, \mathrm{H}_{5}\right), 6.73\left(1 \mathrm{H}, \mathrm{d}, J 2 \mathrm{~Hz}, \mathrm{H}_{7}\right), 6.90(1 \mathrm{H}$, d, $\left.J 2 \mathrm{~Hz}, \mathrm{H}_{6}\right), 6.92(1 \mathrm{H}, \mathrm{s}, \mathrm{H} \alpha), 7.64(1 \mathrm{H}, \mathrm{d}, J 8 \mathrm{~Hz}$, $\left.\mathrm{H}_{4}\right), 7.80\left(1 \mathrm{H}, \mathrm{d}, J 2 \mathrm{~Hz}, \mathrm{H}_{2}\right.$ ). This was identified as $5^{\prime}$-chloro-sulfuretin (10) through direct comparison of spectral data with those of the authentic sample, which was obtained by condensation ${ }^{21}$ of 4 with 6 .

The methanolic solution $(100 \mathrm{ml})$ of $240 \mathrm{mg}$ of 4 and $140 \mathrm{mg}$ of 6 was adjusted with $\mathrm{HCl}$ to $\mathrm{pH} 2.5$ and stood for $40 \mathrm{~min}$ under stirring. To the equilibrium mixture a large volume of water was added and this was extracted with EtOAc. After evaporation of the solvent the residue $(374 \mathrm{mg})$ was chromatographed on a silica-gel column (solvent A) to afford $50 \mathrm{mg}$ of 10 and $34 \mathrm{mg}$ of 9.

$\mathrm{ClO}_{2}$ treatment of 9 . Quantitative determination of the individual component in the reaction mixture was made by Iatron-chromatoscanner using the developing solvents (benzene-ethyl acetate - formic acid $=20: 4: 1)$.

The compound (9) $(400 \mathrm{mg})$ was dissolved in $60 \mathrm{ml}$ of $t-\mathrm{BuOH}$, to which $50 \mathrm{ml}$ of $\mathrm{ClO}_{2}$ solution (4.4 mmol) was added under stirring. After standing for five minutes at $60^{\circ} \mathrm{C}$ the reaction mixture was diluted with a large volume of water and this was extracted with ethyl ether $\left(\mathrm{Et}_{2} \mathrm{O}\right)$. After evaporation of the solvent the residue ( $426 \mathrm{mg}$ ) was subjected to the preparative TLC (PLC: solvent A) for isolation 
and further purification of the reddish compound (15). (Yield $22 \%$ ). MS: $454(\mathrm{M}+2), 452(\mathrm{M})$. Found: C $57.25 ; \mathrm{H} 3.60$. Calc. $\mathrm{C}_{23} \mathrm{H}_{13} \mathrm{O}_{8} \mathrm{Cl} \cdot 3 / 2 \mathrm{H}_{2} \mathrm{O}: \mathrm{C}$ 57.56; H 3.36. UV [abs. $\mathrm{MeOH}(\log \varepsilon)]: 260(3.71)$, 373 (3.69), 415 (sh, 241) nm. IR (KBr): 1680, 1640, $1600 \mathrm{~cm}^{-1}$. On reduction with $\mathrm{NaBH}_{4}$ by the usual manner this afforded 9.

The methanolic solution $(20 \mathrm{ml})$ of $15(80 \mathrm{mg})$ was adjusted with dilute $\mathrm{HCl}$ to $\mathrm{pH} 4.0$ and stood for 10 min at $60^{\circ} \mathrm{C}$ under stirring. After dilution with a large volume of water the resulting solution was extracted with $\mathrm{Et}_{2} \mathrm{O}$, and the solvent was evaporated to dryness. The residue was subjected to PLC (solvent A) and this yielded $15 \mathrm{mg}$ of 6hydroxy-coumaranone (4) and $28 \mathrm{mg}$ of the reddish powder (16), which newly appeared, m.p. (d.p.) $250^{\circ} \mathrm{C}$. MS: $304(\mathrm{M}+2), 302(\mathrm{M})$. Found: C 55.88; H 3.08; $\mathrm{Cl}$ 11.82. Calc. for $\mathrm{C}_{15} \mathrm{H}_{7} \mathrm{O}_{5} \mathrm{Cl} \cdot \mathrm{H}_{2} \mathrm{O}: \mathrm{C}$ 56.17; H 2.83; Cl 11.73. UV [abs. MeOH $(\log \varepsilon)]: 268(3.32)$, 370 (3.67), 445 (sh, 2.90) nm. IR (KBr): 1685, 1660, $1590 \mathrm{~cm}^{-1}$.

The solution of $16(20 \mathrm{mg})$ in pyridine $(1 \mathrm{ml})$ was mixed with a solution of $o$-phenylenediamine $(15$ $\mathrm{mg})$ in the same solvent $(0.2 \mathrm{ml})$. After standing for 1 $h$ at room temperature a part of the solvent was removed under reduced pressure. On addition of water it gave a crystalline precipitate which was recrystallized from $\mathrm{MeOH}-\mathrm{H}_{2} \mathrm{O}$. Red crystalline powder, m.p. over $270^{\circ} \mathrm{C}$. MS: $374(\mathrm{M})$. Found: C $66.88 ; \mathrm{H} 3.12 ; \mathrm{N}$ 7.21. Clac. for $\mathrm{C}_{21} \mathrm{H}_{11} \mathrm{O}_{3} \mathrm{~N}_{2} \mathrm{Cl}$ : C $67.29 ; \mathrm{H} 2.96 ; \mathrm{N}$ 7.47. UV [abs. $\mathrm{MeOH}(\log \varepsilon)]: 256$ (3.63), 352 (3.62), 415 (sh, 3.28) nm. IR (KBr): 1680, $1600,840,760 \mathrm{~cm}^{-1}$. Reduction of 16 with $\mathrm{NaBH}_{4}$ yielded 10

Reaction of 16 in weakly-acidic solution at $60^{\circ} \mathrm{C}$. The compound (16) $(2.15 \mathrm{~g})$, prepared by the treatment of 10 with $\mathrm{NaIO}_{4},{ }^{13}$ was dissolved in $100 \mathrm{ml}$ of $\mathrm{MeOH}$ and the methanolic solution was adjusted with dilute $\mathrm{HCl}$ to $\mathrm{pH} 4.0$ and stood for $30 \mathrm{~min}$ at $60^{\circ} \mathrm{C}$. The solution was evaporated to small volume and extracted with $\mathrm{Et}_{2} \mathrm{O}$. The etherial solution was washed sufficiently with water and dried over $\mathrm{Na}_{2} \mathrm{SO}_{4}$ and then evaporated to dryness. The extracts $(2.11 \mathrm{~g})$ were chromatographed on silica-gel column (solvent A) to afford $133 \mathrm{mg}$ of I, $80 \mathrm{mg}$ of II, and $485 \mathrm{mg}$ of III. Recrystallization of II from $\mathrm{MeOH}-\mathrm{H}_{2} \mathrm{O}$ gave yellow powder, m.p. over $270^{\circ} \mathrm{C}$. This was identified as $5^{\prime}$-chloro-sulfuretin (10) by comparing the mass and IR spectra with those of an authentic sample.

The product III (20) was purified by the repeated PLCs (solvent A). Found: C 57.44; $\mathrm{H} 2.85$. Calc. for $\mathrm{C}_{30} \mathrm{H}_{14} \mathrm{O}_{10} \mathrm{Cl}_{2} \cdot \mathrm{H}_{2} \mathrm{O}: \mathrm{C}$ 57.79; $\mathrm{H}$ 2.59. UV [abs. $\mathrm{MeOH}(\log \varepsilon)$ ]: 271 (3.91), 348 (4.11), 410 (sh, 3.16) $\mathrm{nm}$. IR (KBr): 1700, 1660, 1640, 1600, 1420 (dioxene $\mathrm{C}-\mathrm{O}$ band ${ }^{22}$ ).

The solution of $20(50 \mathrm{mg})$ in pyridine $(3 \mathrm{ml})$ was mixed with the solution of o-phenylenediamine ( 30 $\mathrm{mg})$ in the same solvent $(0.5 \mathrm{ml})$. After standing for 1 $\mathrm{h}$ at room temperature the solvent was evaporated to dryness under reduced pressure. Recrystallization of the residue from $\mathrm{MeOH}$ gave reddish crystalline powder, m.p. over $270^{\circ} \mathrm{C}$. MS: 676 (M). Found: C 63.45; H 2.87; N 3.98. Calc. for $\mathrm{C}_{36} \mathrm{H}_{18} \mathrm{O}_{8} \mathrm{~N}_{2} \mathrm{Cl}_{2}$ : C 63.82; $\mathrm{H} \mathrm{2.68;} \mathrm{N}$ 4.13. This adduct (21) was acetylated with acetic anhydride and pyridine to afford the acetate (22), which was recrystallized from $\mathrm{MeOH}$ to yield brown powder, m.p. $167-170^{\circ} \mathrm{C}$. MS: 718 (M). Found: C 62.76; H 3.18; N 3.50. Calc. for $\mathrm{C}_{40} \mathrm{H}_{22} \mathrm{O}_{10} \mathrm{~N}_{2} \mathrm{Cl}_{2}: \mathrm{C} 63.08 ; \mathrm{H}$ $2.91 ; \mathrm{N} 3.68 .{ }^{1} \mathrm{H}$ NMR $\left(\mathrm{CDCl}_{3}\right): \delta 2.31(6 \mathrm{H}, \mathrm{s}, \mathrm{OAx}$ $\times 2), 5.81\left(1 \mathrm{H}, \mathrm{s}, \mathrm{H}_{\delta}\right), 6.70-7.10(6 \mathrm{H}, \mathrm{m}), 7.10-7.38$ $(4 \mathrm{H}, \mathrm{m}), 7.42-8.20(6 \mathrm{H}, \mathrm{m})$.

Reduction of III $(420 \mathrm{mg})$ gave the yellow compound 18 , which was acetylated with acetic anhydride and pyridine to yield the acetate. The latter was recrystallized from $\mathrm{MeOH}$ to afford yellow crystalline powder $17(310 \mathrm{mg})$, m.p. 163 $-165^{\circ} \mathrm{C}$. FD-Mass: 820 (M). Found: C 58.54; $\mathrm{H}$ 3.18. Calc. for $\mathrm{C}_{30} \mathrm{H}_{13} \mathrm{O}_{5} \mathrm{Cl}_{2}\left(\mathrm{OCOCH}_{3}\right)_{5}$ : C 58.61; $\mathrm{H}$ 3.44. UV [abs. $\mathrm{MeOH}(\log \varepsilon)]: 266(4.20), 330$ (4.07), 365 (4.00), 381 (4.03) nm. IR (KBr): 1780, 1735 , $1710,1650,1440,1416 \mathrm{~cm}^{-1} .{ }^{1} \mathrm{H}$ NMR $\left(\mathrm{CDCl}_{3}\right): \delta$ $2.30(15 \mathrm{H}, \mathrm{s}, \mathrm{OAc} \times 5), 5.88\left(1 \mathrm{H}, \mathrm{d}, J 8 \mathrm{~Hz}, \mathrm{H}_{\gamma}\right), 5.93(1 \mathrm{H}$, $\left.\mathrm{d}, J 8 \mathrm{~Hz}, \mathrm{H}_{\delta}\right), 6.79\left(1 \mathrm{H}, \mathrm{d}, J 2 \mathrm{~Hz}, \mathrm{H}_{3},{ }^{\prime \prime}, 6.90(1 \mathrm{H}, \mathrm{d}, J\right.$ $\left.2 \mathrm{~Hz}, \mathrm{H}_{2}, \cdots\right), 6.96\left(1 \mathrm{H}, \mathrm{dd}, J 8 \mathrm{~Hz}, \mathrm{H}_{6}\right), 7.20(1 \mathrm{H}, \mathrm{d}, J 2$ $\left.\mathrm{Hz}, \mathrm{H}_{8}\right), 7.24(1 \mathrm{H}, \mathrm{s}, \mathrm{H} \alpha), 7.26\left(1 \mathrm{H}, \mathrm{d}, J 2 \mathrm{~Hz}, \mathrm{H}_{2},\right), 7.54$ $\left(1 \mathrm{H}, \mathrm{dd}, J 8 \mathrm{~Hz}, \mathrm{H}_{5^{\prime}}\right), 7.59\left(1 \mathrm{H}, \mathrm{d}, J 8 \mathrm{~Hz}, \mathrm{H}_{6^{\prime \prime}}\right), 7.80$ $\left(1 \mathrm{H}, \mathrm{d}, J 8 \mathrm{~Hz}, \mathrm{H}_{5}\right), 7.81\left(1 \mathrm{H}, \mathrm{d}, J 2 \mathrm{~Hz}, \mathrm{H}_{6}, \cdot\right), 8.12(1 \mathrm{H}$, $\left.\mathrm{d}, \mathrm{J} 2 \mathrm{~Hz}, \mathrm{H}_{6}\right) \cdot{ }^{13} \mathrm{C}$ NMR (carbon number): $\delta 71.55$ $(\gamma), 97.87(\delta), 104.25\left(3^{\prime \prime}\right), 107.12(7), 110.27(5), 115.48$ $\left(6^{\prime \prime}\right), 118.06\left(2^{\prime \prime \prime}\right), 118.58(\alpha), 118.62\left(6^{\prime \prime \prime}\right), 119.87\left(1^{\prime \prime \prime}\right)$, $121.39\left(5^{\prime \prime}\right), 124.78(3 \mathrm{a}), 125.20(4), 125.43\left(2^{\prime}\right), 126.25$ $\left(1^{\prime \prime}\right), 127.54\left(5^{\prime \prime \prime}\right), 128.24\left(5^{\prime}\right), 128.65\left(6^{\prime}\right), 137.83\left(3^{\prime \prime \prime}\right)$, $140.99\left(1^{\prime}\right), 141.52\left(3^{\prime}\right), 147.77(2), 157.61\left(4^{\prime}\right), 159.56$ $\left(4^{\prime \prime \prime}\right), 159.83\left(2^{\prime \prime}\right), 166.09(6), 166.61\left(4^{\prime \prime}\right), 166.79(7 \mathrm{a})$, $170.01(\beta), 182.06(3)$.

The compound (18) $(400 \mathrm{mg})$ was refluxed with dimethyl sulfate and potassium carbonate in acetone. The solution of the resulting methyl ether (19) $(420 \mathrm{mg})$ in dichloromethane was cooled in ice and subjected to the treatment with ozonized oxygen $\left(40 \mathrm{mmol}\right.$ of $\left.\mathrm{O}_{3}\right)$. The resulting mixture was decomposed by addition of $10 \% \quad \mathrm{H}_{2} \mathrm{O}_{2}$ $-\mathrm{CH}_{3} \mathrm{COOH}$. After addition of water the solution was extracted with EtOAc. The extracts $(353 \mathrm{mg})$ were chromatographed on silica-gel column (solvent A) to yield three products, 38, 23, and 135 $\mathrm{mg}$. Each of the former two was recrystallized from $\mathrm{MeOH}-\mathrm{H}_{2} \mathrm{O}$ to yield colorless needles, m.p. 158 $-159^{\circ} \mathrm{C}$ and m.p. $107-108^{\circ} \mathrm{C}$, respectively. The former was identified as 4-methoxy-salicylic acid (23) (lit. m.p. $159^{\circ} \mathrm{C}^{23}$ ), the latter as 2,4-dimethoxybenzoic acid (24) (lit. m.p. $107-108^{\circ} \mathrm{C}^{24}$ ) by comparing the mixed m.p. IR with those of authentic samples, respectively. 
The third product $(135 \mathrm{mg})$ dissolved in aqueous sodium hydroxide $(100 \mathrm{ml})$ was mixed with $200 \mathrm{ml}$ of potassium permanganate solution $(5 \%)$ under stirring and stood overnight at room temperature. The solution was then acidified and extracted with $\mathrm{Et}_{2} \mathrm{O}$. The solvent was evaporated to dryness to afford a single compound ( $24 \mathrm{mg}$ ), which was recrystallized from $\mathrm{MeOH}$ to yield colorless powder, m.p. $189-190^{\circ} \mathrm{C}$. This was identified as 5chloro-veratric acid ${ }^{25}$ by comparing the mixed m.p. and IR with those of an authentic sample.

Analyses of IV, 26. After elution of I-III the residual column was washed well with solvent $A$ to remove impurities. Subsequently IV was eluted with EtOAc-HCOOH $(1: 1)$ and the solvents were evaporated to dryness. The resulting compound $(270 \mathrm{mg})$ was purified repeatedly by precipitation with $\mathrm{CHCl}_{3}$ to yield $174 \mathrm{mg}$ of 26 . Found: $\mathrm{C} 58.77 ; \mathrm{H}$ 2.62; $\mathrm{Cl} 12.01$. Calc. for $\left(\mathrm{C}_{15} \mathrm{H}_{7} \mathrm{O}_{5} \mathrm{Cl}\right)_{5} \cdot \mathrm{H}_{2} \mathrm{O}: \mathrm{C}$ $58.81 ; \mathrm{H} 2.44 ; \mathrm{Cl} 11.59$. UV [abs. $\mathrm{MeOH}(\log \varepsilon)]: 272$ (3.10), 325 (sh, 3.00), 410 (sh. 2.62) nm. IR (KBr): 1700 , $1655,1640,1600,1450,1440 \mathrm{~cm}^{-1}$. IV was subjected to gel-permeation chromatography (Sephadex LH20) using $\mathrm{MeOH}-\mathrm{CHCl}_{3}(1: 1)$.

IV 26 was reduced and subsequently acetylated by the same manner as mentioned in the preparation of 17 from III, and the resulting acetate was subjected to the ${ }^{13} \mathrm{C}$ NMR spectroscopy. ${ }^{13} \mathrm{C}$ NMR (carbon number): $\delta 71.11(\gamma), 97.31(\delta), 169.92(\beta)$.

Acknowledgements. The authors are greatly indebted to Professors T. Komori and E. Taniguchi and Dr. E. Kuwano of this University for their kind advice and measurement of FD-Mass and ${ }^{13} \mathrm{C}$ NMR spectra.

This paper is submitted in honour of Professor Holger Erdtman on the occasion of his 80th birthday in appreciation of his contributions to organic chemistry.

\section{REFERENCES}

1. Ohtani, Y., Tachibana, S. and Sumimoto, M. Mokuzai Gakkaishi 26 (1980) 534.

2. Sumimoto, M., Tachibana, S. and Ohtani, Y. Proc. Int. Symp. Wood Pulp. Chem. (The Ekman Days 1981) Vol. 2 (1981) 150.

3. Ohtani, Y., Shutoh, K. and Sumimoto, M. Mokuzai Gakkaishi 28 (1982) 59.

4. Tachibana, S. and Sumimoto, M. Holzforschung 34 (1980) 131.

5. Ohtani, Y., Tachibana, S. and Sumimoto, M. Mokuzai Gakkaishi 26 (1980) 796.

6. Pelter, A., Ward, R. S. and Gray, T. I. J. Chem. Soc. Perkin Trans. 1 (1976) 2475.

7. Ternai, B. and Markham, K. R. Tetrahedron 32 (1976) 565; Ibid. 32 (1976) 2607.
8. Iinuma, M., Matsuura, S. and Kusuda, K. Chem. Pharm. Bull. 28 (1980) 708.

9. Rapson, W. H. Tappi 41 (1958) 4, 181.

10. Otting, W. and Staiger, G. Chem. Ber. 88 (1955) 828.

11. Teuber, H. J. and Staiger, G. Chem. Ber. 88 (1955) 802.

12. Willstätter, R. and Müller, H. E. Chem. Ber. 44 (1911) 2182.

13. Adler, E., Magnusson, R., Berggren, B. and Thomelius, H. Acta Chem. Scand. 14 (1960) 515.

14. Horspool, W. H., Tedder, J. M. and Din, Z. U. J. Chem. Soc. (1968) 1597.

15. Horspool, W. H., Tedder, J. M. and Din, Z. U. J. Chem. Soc. (1969) 1692.

16. Friedrichsen, W. Tetrahedron Lett. (1969) 4425.

17. Cava, M. P. and Vanmeter, J. P. J. Org. Chem. 34 (1969) 538.

18. Tachibana, S. and Sumimoto, M. Mokuzai Gakkaishi 28 (1982) 45.

19. Leopold, B. and Mutton, D. B. Tappi 42 (1959) 218.

20. Anhoury, M. L., Crooy, P., Neys, R. D. and Eliaers, J. J. Chem. Soc. Perkin Trans. 1 (1974) 1015.

21. Nordtsröm, C. G. and Swain, T. Arch. Biochem. Biophys. 60 (1956) 329.

22. Lown, J. W. and Aidov, A. S. K. Can. J. Chem. 44 (1966) 2507.

23. Dean, F. M. and Manunapichu, K. J. Chem. Soc. (1957) 3112.

24. King, F. E. and Grundon, M. F. J. Chem. Soc. (1949) 3348.

25. Kapadia, A. K. and Wiese, G. A. Chem. Abstr. 59 (1962) 501.

Received February 19, 1982.

Acta Chem. Scand. B 36 (1982) No. 9 